\title{
Transesterification of Sago Starch Using Various Fatty Acid Methyl Esters in Densified $\mathrm{CO}_{2}$
}

\author{
Erik Hermawan, Lenna Rosyanti, Leonita Megasari, Asaf Kleopas Sugih, and Henky Muljana
}

\begin{abstract}
Starch fatty acid esters, a biodegradable and a renewable thermoplastics materials, are commonly synthesized in organic solvents that have high environmental impact. This manuscript describes an exploratory study on the synthesis of starch esters using various fatty acid methyl esters (FAME) such as methyl myristate, methyl laurate, methyl oleate and methyl palmitate in densified carbon dioxide as a green solvent. A series of experiments were conducted in order to investigate the influence of temperature $\left(100{ }^{\circ} \mathrm{C}, 110{ }^{\circ} \mathrm{C}, 120{ }^{\circ} \mathrm{C}\right)$, pressure $(100$ bar, 120 bar, 150 bar) and type of methyl esters on reactivity and the characteristics of the products. Within the experimental range, the highest DS value $(0.45)$ is achieved at pressure of 100 bar, temperature of $120^{\circ} \mathrm{C}$, with methyl palmitate as the reagent In addition, the introduction of fatty acid chains into the starch backbone significantly altered thermal properties of the native sago starch.
\end{abstract}

Index Terms-Transesterification, sago starch, fatty acid methyl ester, densified $\mathrm{CO}_{2}$.

\section{INTRODUCTION}

The high utilization of plastics can cause a serious waste problems since most of the plastics are non biodegradable. Moreover, most of the plastics are synthesized from the unrenewable fossil fuels which again lead to another serious problem [1]. Therefore, there is a strong incentive to find a plastics materials which is biodegradable and also renewable. One alternative which is proposed in this research is to use starch as the raw material. However, before it can be used further as thermoplastic materials, the native starch require a modification processes to improve several important product characteristics, such as hydrophobicity, mechanical strength and certain thermal properties [1]-[3].

Among others, an esterification of starch with a various fatty acid esters such as fatty acid vinyl ester (FAVE), fatty acid methyl ester (FAME), and fatty acid chloride in organic solvent has resulted with a product with a better thermoplastics properties compare to their native properties [1]-[8]. The disadvantages on the available processes are the application of the organic solvent that has a high environmental impact and also the difficulties on the product work-up [2].

To overcome these problems, the potential used of

Manuscript received August 9, 2014; revised October 12, 2014. This work was financially supported by Research Grant from Indonesian Directorate General of Higher Education (DIKTI). The authors aknowledge Prof. H. J. Heeres (University of Groningen), Prof. F.Picchioni (University of Groningen) and Prof. L. P. B. M. Janssen (University of Groningen) for stimulating discussion.

The authors are with the Chemical Engineering Department, Parahyangan Catholic University, Bandung 40141, West Java, Indonesia (coresponding author: Erik Hermawan; e-mail: hmuljana@gmail.com). densified $\mathrm{CO}_{2}$ as the solvent for the starch modification with the fatty acid esters has been recently reported [2]. The authors reported that the esterification of potato starch with methyl laurate and methyl oleate is successful [2] However, the degree of substitution (DS) of the products is still relatively low (DS $0.03-0.04$ ) and have a poor mechanical properties [2].

This work aims to explore the application of sago starch as a raw material in the fatty acid esters synthesis. Sago starch known to have a type $\mathrm{C}$ crystal structure which is less pressure resistant [9] and hopefully improve the reactivity. The relevant product properties were analyzed using Fourier Transform Infra Red (FT-IR) spectroscopy, Scanning Electron Microscope (SEM), Thermal Gravimetry Analysis (TGA) and Differential Scanning Calorimetry (DSC).

\section{MATERIAL AND METHOD}

\section{A. Material}

Sago starch was purchased from Bina Sago Lestari (Indonesia). The water content was determined by gravimetri method and was found to be $16.9 \% \mathrm{wt} / \mathrm{wt}$. Analytical grade methyl laurate, methyl palmitate, methyl myristate and methyl oleate were purchased from Sigma Aldrich. Analytical grade potassium carbonate was purchased from Merck. Technical grade methanol was purchased from Bratachem (Indonesia). All chemicals were used as received without further purification. High purity $\mathrm{CO}_{2}$ ( $\geq 98 \%$ volume) and $\mathrm{N}_{2}(\geq$ $98 \%$ volume) were purchased from Sangkuriang (Indonesia).

\section{B. Experimental Set-up}

The experimetal set up setup consists of a high pressure reactor (max volume of $35 \mathrm{ml}$ ), an electrical heating element with temperature controller, and a high pressure pump unit (Chrom Tech). The reactor has a temperature range from 30 ${ }^{\circ} \mathrm{C}$ to $300^{\circ} \mathrm{C}$ and a maximum pressure of $200 \mathrm{bar}$. A positive displacement pump (Chrom Tech) with a maximum flow rate of $24 \mathrm{ml} / \mathrm{min}$ and a maximum pressure of $690 \mathrm{bar}$ is equipped with an integrated cooling system to eliminate the cavitation problem in the pump.

\section{Experimental Procedures}

The fatty acid starch esters were prepared by reacting native sago starch (2.5 g, dry basis) with methyl laurate, methyl myristate, methyl palmitate, or methyl oleate (3 $\mathrm{mol} / \mathrm{mol}$ anhydroglucose unit (AGU)) using $\mathrm{K}_{2} \mathrm{CO}_{3}(0.1$ $\mathrm{mol} / \mathrm{mol} \mathrm{AGU}$ ) as the catalyst. All materials were charged to the high pressure reactor. Prior the experiments, $\mathrm{N}_{2}$ was used to remove traces of air from the reactor. Subsequently, the autoclave was heated and pressurized with $\mathrm{CO}_{2}$ to reach the 
desired level. After reaction, the reactor was cooled down to room temperature, depressurized, followed by the product-work up according to a procedure described elsewhere [2].

\section{Analytical Equipment}

Fourier Transform Infrared (FT-IR) spectra were acquired on a FTIR Prestige 21 Shimadzu. TGA measurements were performed on a TGA Mettler Toledo Type TGA/SDTA 851. The samples were heated to $900{ }^{\circ} \mathrm{C}$ in an inert atmosphere at a heating rate of $10{ }^{\circ} \mathrm{C} \mathrm{min}^{-1}$. DSC analysis were done on a Perkin Elmer type DSC 8000. The samples(4-5 mg) were heated from $0{ }^{\circ} \mathrm{C}$ to $200{ }^{\circ} \mathrm{C}$ with a heating rate of $10{ }^{\circ} \mathrm{C} \mathrm{min}{ }^{-1}$. The morphology of native starch and starch fatty acid esters products were determined using Scanning Electron Microscope on JEOL T330A.

\section{E. Determination of DS of the Products}

The DS values were determined using a hydrolysis method according to a literature procedure [10]. The DS was calculated using the following equation [10]:

$$
D S=\frac{162\left(V_{\text {NaOH. }} N_{\text {NaOH }}-V_{\text {HCI }} \mathrm{N}_{\mathrm{HCl}}\right)}{(1000 . W)-M r\left(V_{\text {NaOH. }} \mathrm{N}_{\mathrm{NaOH}}-\mathrm{V}_{\mathrm{HCl}} \cdot \mathrm{N}_{\mathrm{HCl}}\right)}
$$

where $V_{\mathrm{NaOH}}$ is the volume of $\mathrm{NaOH}(\mathrm{ml}), V_{\mathrm{HCl}}$ the titration volume of acid for the fatty acid starch sample $(\mathrm{ml}), N_{\mathrm{NaOH}}$ normality of used $\mathrm{NaOH}, \mathrm{N}_{\mathrm{HCl}}$ normality of used $\mathrm{HCl}$ and $\mathrm{W}$ the mass of the fatty acid starch sample $(\mathrm{g})$.

\section{RESULT AND DISSCUSION}

\section{A. Systematic Studies}

To study the effect of process conditions on the degree of substitution (DS), a number of experiments were performed at various pressures (100-150 bar), temperatures $\left(100-120{ }^{\circ} \mathrm{C}\right)$ and reagents for $1.5 \mathrm{~h}$ reaction time. Furthermore, the effect of the fatty acid chain length (methyl oleate, palmitate, myristate and laurate) and the type of basic catalyst were explored. An overview of the experimental conditions and results are given in Table I.

\section{1) Effect of pressure and temperature on degree of substitution $(D S)$ value}

As can be seen in Table I, it is obvious that at the higher pressure, the DS of the starch oleate products show different trend compared with starch palmitate, starch laurate and starch myristate. In addition, an optimum value are observed at 120 bar for the starch laurate and starch myristate products. This complex and peculiar behavior can be resulted from an interplay between the plasticizing effect of $\mathrm{CO}_{2}$ and compressive effect at elevated pressures [2], [11].

The plasticizing effect lead to an increase of the rate of diffusion of the reagents inside the starch granules which improve the reactivity (higher DS). While the compressive effect lead to a decrease in the DS value, since the starch granules are compressed and in contrary, reduce the diffusion of the reactant into the starch granules [2], [11].

In contrary with the pressure effect, a clear trend is observed in the experimental results (Table I). It is obvious that DS values increase with temperature in all cases. The higher DS value obtained at higher temperatures may be caused by an increase in the overall reaction rate [2], [12].

TABLE I: OVERVIEW OF EXPERIMENTS

\begin{tabular}{|c|c|c|c|c|c|c|}
\hline No & $\begin{array}{c}\text { Fatty acid } \\
\text { reagent }\end{array}$ & $\begin{array}{c}\begin{array}{c}\text { Pressure } \\
\text { (bar) }\end{array} \\
\end{array}$ & $\begin{array}{c}\text { Temperature } \\
\left({ }^{\circ} \mathrm{C}\right)\end{array}$ & $\mathbf{t}(\mathbf{h})$ & Catalyst & DS \\
\hline 1 & Methyl Myristate & 100 & 100 & 1.5 & $\mathrm{~K}_{2} \mathrm{CO}_{3}$ & 0.034 \\
\hline 2 & Methyl Myristate & 100 & 110 & 1.5 & $\mathrm{~K}_{2} \mathrm{CO}_{3}$ & 0.053 \\
\hline 3 & Methyl Myristate & 100 & 120 & 1.5 & $\mathrm{~K}_{2} \mathrm{CO}_{3}$ & 0.127 \\
\hline 4 & Methyl Myristate & 120 & 100 & 1.5 & $\mathrm{~K}_{2} \mathrm{CO}_{3}$ & 0.096 \\
\hline 5 & Methyl Myristate & 120 & 110 & 1.5 & $\mathrm{~K}_{2} \mathrm{CO}_{3}$ & 0.105 \\
\hline 6 & Methyl Myristate & 120 & 120 & 1.5 & $\mathrm{~K}_{2} \mathrm{CO}_{3}$ & 0.153 \\
\hline 7 & Methyl Myristate & 150 & 100 & 1.5 & $\mathrm{~K}_{2} \mathrm{CO}_{3}$ & 0.088 \\
\hline 8 & Methyl Myristate & 150 & 110 & 1.5 & $\mathrm{~K}_{2} \mathrm{CO}_{3}$ & 0.145 \\
\hline 9 & Methyl Myristate & 150 & 120 & 1.5 & $\mathrm{~K}_{2} \mathrm{CO}_{3}$ & 0.307 \\
\hline 10 & Methyl Laurate & 100 & 100 & 1.5 & $\mathrm{~K}_{2} \mathrm{CO}_{3}$ & 0.035 \\
\hline 11 & Methyl Laurate & 100 & 110 & 1.5 & $\mathrm{~K}_{2} \mathrm{CO}_{3}$ & 0.061 \\
\hline 12 & Methyl Laurate & 100 & 120 & 1.5 & $\mathrm{~K}_{2} \mathrm{CO}_{3}$ & 0.119 \\
\hline 13 & Methyl Laurate & 120 & 100 & 1.5 & $\mathrm{~K}_{2} \mathrm{CO}_{3}$ & 0.031 \\
\hline 14 & Methyl Laurate & 120 & 110 & 1.5 & $\mathrm{~K}_{2} \mathrm{CO}_{3}$ & 0.039 \\
\hline 15 & Methyl Laurate & 120 & 120 & 1.5 & $\mathrm{~K}_{2} \mathrm{CO}_{3}$ & 0.065 \\
\hline 16 & Methyl Laurate & 150 & 100 & 1.5 & $\mathrm{~K}_{2} \mathrm{CO}_{3}$ & 0.045 \\
\hline 17 & Methyl Laurate & 150 & 110 & 1.5 & $\mathrm{~K}_{2} \mathrm{CO}_{3}$ & 0.065 \\
\hline 18 & Methyl Laurate & 150 & 120 & 1.5 & $\mathrm{~K}_{2} \mathrm{CO}_{3}$ & 0.166 \\
\hline 19 & Methyl Oleate & 100 & 100 & 1.5 & $\mathrm{~K}_{2} \mathrm{CO}_{3}$ & 0.068 \\
\hline 20 & Methyl Oleate & 100 & 110 & 1.5 & $\mathrm{~K}_{2} \mathrm{CO}_{3}$ & 0.09 \\
\hline 21 & Methyl Oleate & 100 & 120 & 1.5 & $\mathrm{~K}_{2} \mathrm{CO}_{3}$ & 0.348 \\
\hline 22 & Methyl Oleate & 120 & 100 & 1.5 & $\mathrm{~K}_{2} \mathrm{CO}_{3}$ & 0.08 \\
\hline 23 & Methyl Oleate & 120 & 110 & 1.5 & $\mathrm{~K}_{2} \mathrm{CO}_{3}$ & 0.13 \\
\hline 24 & Methyl Oleate & 120 & 120 & 1.5 & $\mathrm{~K}_{2} \mathrm{CO}_{3}$ & 0.149 \\
\hline 25 & Methyl Oleate & 150 & 100 & 1.5 & $\mathrm{~K}_{2} \mathrm{CO}_{3}$ & 0.147 \\
\hline 26 & Methyl Oleate & 150 & 110 & 1.5 & $\mathrm{~K}_{2} \mathrm{CO}_{3}$ & 0.15 \\
\hline 27 & Methyl Oleate & 150 & 120 & 1.5 & $\mathrm{~K}_{2} \mathrm{CO}_{3}$ & 0.274 \\
\hline 28 & Methyl Palmitate & 100 & 100 & 1.5 & $\mathrm{~K}_{2} \mathrm{CO}_{3}$ & 0.12 \\
\hline 29 & Methyl Palmitate & 100 & 110 & 1.5 & $\mathrm{~K}_{2} \mathrm{CO}_{3}$ & 0.096 \\
\hline 30 & Methyl Palmitate & 100 & 120 & 1.5 & $\mathrm{~K}_{2} \mathrm{CO}_{3}$ & 0.45 \\
\hline 31 & Methyl Palmitate & 120 & 100 & 1.5 & $\mathrm{~K}_{2} \mathrm{CO}_{3}$ & 0.048 \\
\hline 32 & Methyl Palmitate & 120 & 110 & 1.5 & $\mathrm{~K}_{2} \mathrm{CO}_{3}$ & 0.079 \\
\hline 33 & Methyl Palmitate & 120 & 120 & 1.5 & $\mathrm{~K}_{2} \mathrm{CO}_{3}$ & 0.13 \\
\hline 34 & Methyl Palmitate & 150 & 100 & 1.5 & $\mathrm{~K}_{2} \mathrm{CO}_{3}$ & 0.07 \\
\hline 35 & Methyl Palmitate & 150 & 110 & 1.5 & $\mathrm{~K}_{2} \mathrm{CO}_{3}$ & 0.097 \\
\hline 36 & Methyl Palmitate & 150 & 120 & 1.5 & $\mathrm{~K}_{2} \mathrm{CO}_{3}$ & 0.11 \\
\hline
\end{tabular}

Table II summarize the experimental results obtained from the literature. It is clear that the DS values obtained in this experiments are significantly higher compared with the one reported in literature (Table II). This imply that within the same experimental range, sago starch is far more reactive compared with potato starch.

TABLE II: EXPERIMENTAL RESULTS FROM LITERATURE

\begin{tabular}{ccccccc}
\hline No & $\begin{array}{c}\text { Experimental } \\
\text { Conditions } \\
\left(\mathrm{P}, \mathrm{bar}, \mathrm{T},{ }^{\circ} \mathrm{C}\right)\end{array}$ & $\begin{array}{c}\text { Type of } \\
\text { FAME }\end{array}$ & $\begin{array}{c}\text { Type of } \\
\text { Starch }\end{array}$ & $\begin{array}{c}\text { Reaction } \\
\text { time }(\mathrm{h})\end{array}$ & DS & Literature \\
\hline 1 & 150 bar, $150{ }^{\circ} \mathrm{C}$ & $\begin{array}{c}\text { Metil } \\
\text { Laurat } \\
2\end{array}$ & Potato & 18 & 0.03 & {$[2]$} \\
\hline & 150 bar, $150{ }^{\circ} \mathrm{C}$ & $\begin{array}{c}\text { Metil } \\
\text { Oleat }\end{array}$ & Potato & 18 & 0.04 & {$[2]$} \\
\hline
\end{tabular}

\section{2) Effect of fatty acid chain length on DS value}

It is clear from Table I and Fig 1 that DS value is a function of the fatty acid chain length as also observed in the literature [2]. It is apparent that the DS values increases at longer fatty acid chain although a few discrepancies existed in the results.

The discrepancies may be related to the positive and negative effect of longer fatty acid chain on the reactivity. The positive effect is caused by a higher plasticizing effect at a longer fatty acid chain resulting with an increase in the diffusion of the reagent inside the starch granules [2], [4] and eventually a higher DS values. In the other hand, a longer fatty acid chain may result with a higher steric hindrance [5], [6] compared with the shorter chain length and reduced the diffusion rate of the reagent [2], [5], [6]. The interplay 
between these two opposite effect plays role and will influence the reaction [2].

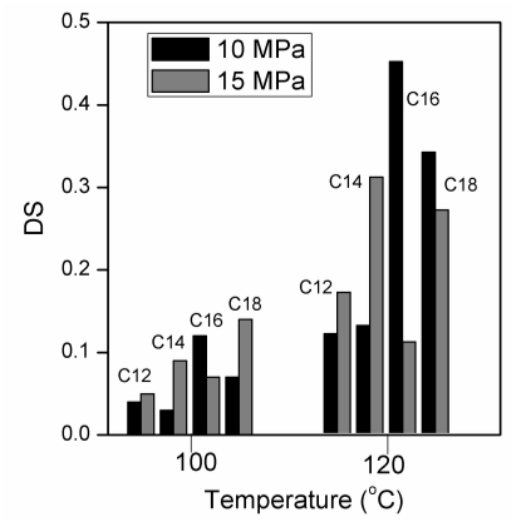

Fig. 1. DS value at the different fatty acid chain length.

\section{B. Product Characterization}

\section{1) FT-IR analysis}

Fig. 2 shows FT-IR spectra for native sago starch, starch laurate and starch myristate. It is clear from Fig. 2, all of the spectra show a strong absorption band at $2800-2950 \mathrm{~cm}^{-1}(\mathrm{CH}$ stretching) and $3300-3600 \mathrm{~cm}^{-1}$ (OH stretching) which are the typical absorption band for starches [2]. In addition, the spectra of starch laurate and starch myristate show a shoulder at $1750-1800 \mathrm{~cm}^{-1}$ which confirm the presence of the carbonyl $(\mathrm{C}=\mathrm{O}$ stretching $)$ group from the fatty acid chain in the products [2].

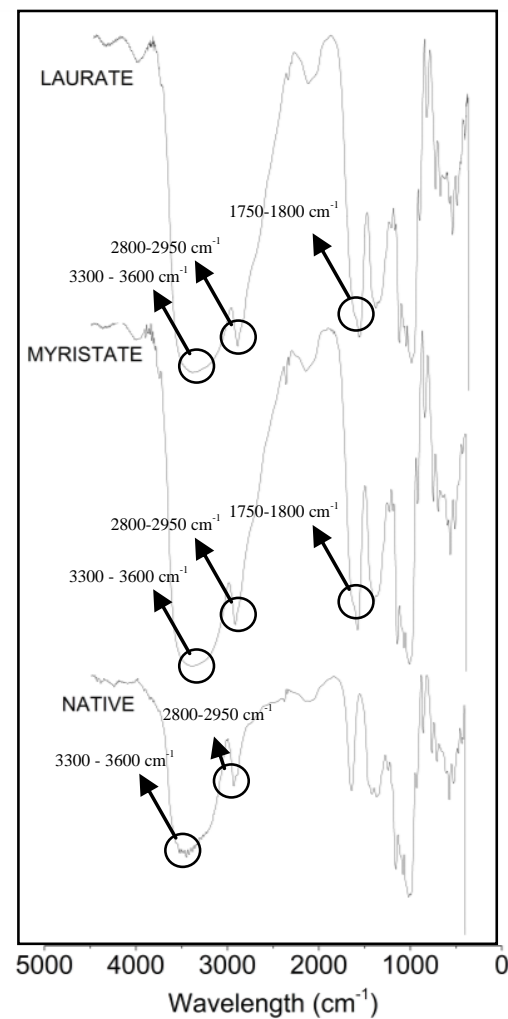

Fig. 2. FT-IR spectra of native sago starch, starch myristate and starch laurate.

\section{2) Scanning electron microscope (SEM)}

Scanning electron microscopy (SEM) was used in order to study the changes in the surface of the starch ester compared with the surface of the of native starch.

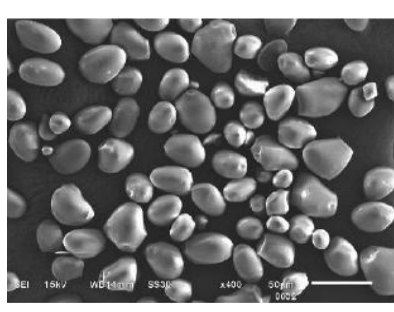

(a)

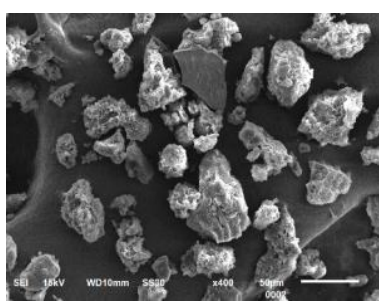

(c)

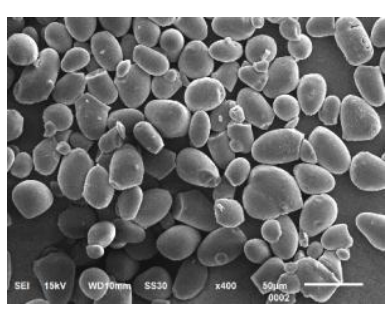

(b)

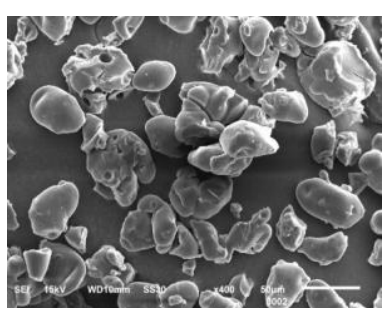

(d)

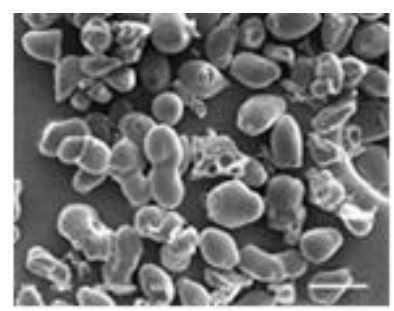

(e)

Fig. 3. SEM of native starch (a), starch oleate (b), starch palmitate (c), starch laurate (d), and starch myristate (e).

It can be seen in Fig. 3, native sago starch has an oval shape granule with a clear distance between each granules. The granules tend to agglomerate with each other as observed in the starch oleate, starch palmitate, starch laurate and starch myristate (Fig. 3b-3e). The fusion of the granules is related to an increase of the hydrogen bond in the starch macromolecules due to the presence of the carbonyl group [13].

\section{3) Thermal gravimetric analysis (TGA)}

Thermal gravimetric analysis (TGA) was done in order to evaluate the thermal stability of the starch ester products. The typical thermogram of native sago starch and sago starch laurate is shown in Fig. 4. It is clear that native starch (280 $290{ }^{\circ} \mathrm{C}$ ) has a higher initial degradation temperature compared with starch laurate $\left(240-250{ }^{\circ} \mathrm{C}\right)$, starch palmitate $\left(230-240{ }^{\circ} \mathrm{C}\right)$ and starch oleate $\left(220-230{ }^{\circ} \mathrm{C}\right)$ as shown in Table III. The decrease of the initial degradation temperature is possibly due to the disintegration of intramolecular interactions such as hydrogen bond in the starch matrices during the reaction [2].

TABLE III: DEGRADATION TEMPERATURE OF STARCH AND ITS DERIVATIVES

\begin{tabular}{cccc}
\hline \hline No & Samples & DS & $\begin{array}{c}\text { Initial } \\
\text { Degradation } \\
\text { Temperature } \\
\left.\mathbf{(}^{\mathbf{0}} \mathbf{C}\right)\end{array}$ \\
\hline 1 & Native Sago & - & $280-290$ \\
2 & Starch & & $240-250$ \\
3 & Starch Laurate & 0.22 & $230-240$ \\
4 & Starch Palmitate & 0.09 & $220-230$ \\
\hline \hline
\end{tabular}

By comparing the TGA results of starch laurate (DS 0.22) and starch oleate (DS 0.19), it is obvious that the longer fatty acid chain reduce the initial degradation temperature of the 
products suggesting a higher disintegration of hydrogen bond in the starch chain.

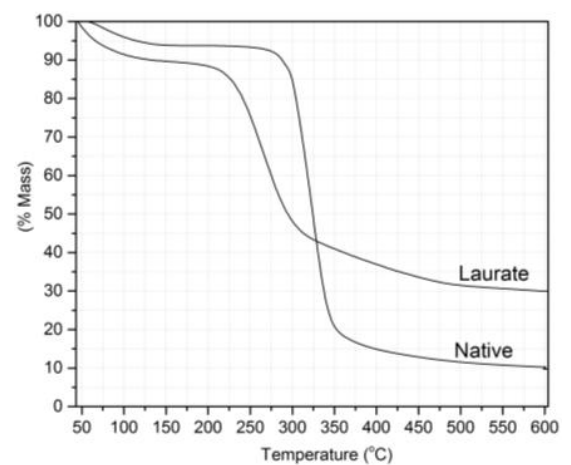

Fig. 4. Thermogram of native starch and starch laurate.

\section{4) Differential Scanning Calorimetry (DSC)}

Beside thermal stability, the changes in the glass transition temperature $\left(\mathrm{T}_{\mathrm{g}}\right)$ of the products are also important to be evaluated. The high glass transition temperature of starch cause the brittleness of the material which is unfavorable and therefore has to be reduced.

Table IV shows $T_{g}$ values of the native sago starch, starch laurate and starch oleate. Native sago starch has a relatively high $\mathrm{T}_{\mathrm{g}}\left(165.5^{\circ} \mathrm{C}\right)$ compared with the one from the products which are $81.11{ }^{\circ} \mathrm{C}$ and $59.34{ }^{\circ} \mathrm{C}$ for starch laurate and starch oleate, respectively. The decrease in the $\mathrm{T}_{\mathrm{g}}$ of the products may be related to the presence of the fatty acid chain in the starch back bone which acts as an internal plasticizer [3]. In addition, at the relatively same DS, the plasticizing effect is higher for the longer fatty acid chain which lead to the lower $\mathrm{T}_{\mathrm{g}}$ value (Table IV) [2], [3].

TABLE IV: GLASS TRANSITION TEMPERATURE OF STARCH AND ITS DERIVATIVES

\begin{tabular}{|c|c|c|c|}
\hline No & Samples & DS & $\begin{array}{c}\text { Glass } \\
\text { Transition } \\
\text { Temperature } \\
\left(\mathrm{Tg},{ }^{\circ} \mathrm{C}\right)\end{array}$ \\
\hline 1 & $\begin{array}{c}\text { Native Sago } \\
\text { Starch }\end{array}$ & - & $165.5^{\mathrm{a}}$ \\
\hline 2 & Starch Laurate & 0.22 & 81.11 \\
\hline 3 & Starch Oleate & 0.19 & 59.34 \\
\hline
\end{tabular}

\section{CONCLUSION}

This paper reports a preliminary study on the transesterification of sago starch with a different FAME (methyl laurate, methyl myristate, methyl palmitate and methyl oleate), a various temperatures $\left(100-120{ }^{\circ} \mathrm{C}\right)$ and pressure values (100-150 bar) in densified $\mathrm{CO}_{2}$. The analysis with a FT-IR shows the presence of carbonyl group in the products suggesting that the reaction is succesfull. It is clear that temperature, pressure, and different fatty acid chain give a significant influence on the DS value although with a different trend. Within the experimental range, a maximum DS value of 0.45 is accessible which indicates a higher reactivity of sago starch compared with potato starch. In addition, the starch ester products have a lower initial degradation and glass transition temperature compared with their native properties.

This study shows a potential used of sago starch as a raw material for the thermoplastic starch. However, further study need to be done in order to improve the DS values and the thermal stability of the products.

\section{REFERENCES}

[1] A. K. Sugih, "Synthesis and properties of starch based biomaterials," Ph.D dissertation, Dept. Chem. Eng, University of Groningen, the Netherlands, 2008

[2] H. Muljana, S. van der Knoop, D. Keijzer, F. Picchioni, L. Janssen, and H. J. Heeres, "Synthesis of fatty acid starch esters in supercritical carbon dioxide," Carbohydrate Polymers, vol 82, no. 2, pp. 346-354, 2010.

[3] H. Winkler, W. Vorwerg, and R. Rihm, "Thermal and mechanical properties of fatty acid starch esters," Carbohydrate Polymers, vol. 102, pp. 941-949, 2014.

[4] A. D. Sagar and E. W. Merrill, "Properties of fatty-acid esters of starch," Journal of Applied Polymer Science, vol 58, no. 9, pp. 1647-1656, 1995

[5] J. Aburto and I. Alric, "Preparation of long-chain esters of starch using fatty acid chlorides in the absence of an organic solvent," Starch-Starke, vol. 51, no. 4, pp. 132-135, 1995.

[6] J. Aburto and I. Alric, "Organic solvent-free transesterification of various starches with lauric acid methyl ester and triacyl glycerides," Starch-Starke, vol. 57, no. 3-4, pp. 145-152, 2005.

[7] H. Winkler, W. Vorwerg, and H. Wetzel, "Synthesis and properties of fatty acid starch esters," Carbohydrate Polymers, vol. 98, no. 1, pp. 208-216, 2013.

[8] A. O. Ashogbon and E. T. Akintayo, "Recent trend in the physical and chemical modification of starches from different botanical sources: A review," Starch-Starke, vol. 66, no. 1-2, pp. 41-57, 2014.

[9] H. Muljana, "Starch modification in supercritical $\mathrm{CO}_{2}$," $\mathrm{Ph} . \mathrm{D}$ dissertation, Dept. Chem. Eng., University of Groningen, the Netherlands, 2010.

[10] W. Xie and Y. Wang, "Synthesis of high fatty acid starch esters with 1-butyl-3-methylimidazolium chloride as a reaction medium," Starch - Stärke, vol. 63, no. 4, pp. 190-197, 2011

[11] M. F. Kemmere and T. Meyer, Supercritical Carbon Doixide in Polymer Reaction Engineering, Weinheim, Germany: WILEY-VCH, 2005.

[12] R. Stute, "Effects of high pressure treatment on starches," Starch Starke, vol. 48, no. 11-12, pp. 399-408, 1996.

[13] J. Singh, L. Kaur, and N. Singh, "Effect of acetylation on some properties of corn and potato starches," Starch-Starke, vol. 56, no. 12, pp. 586-601, 2004.

[14] B. Kaur, A. Fazilah, and A. A. Karim, "Alcoholic-alkaline treatment of sago starch and its effect on physicochemical properties," Food and Bioproducts Processing, vol. 89, no. 4, pp. 463-471, 2011.

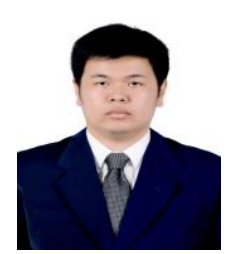

Erik Hermawan was born in Sumedang on September 11, 1992. He finished high school in Mardi Yuana senior high school in Sukabumi and continued his education in Parahyangan Catholic University. He earned his bachelor's degree from the Department of Chemical Engineering, Parahyangan Catholic University, Bandung in 2014. During his study at Parahyangan Catholic University, he was actively participating in lab works as a lab assistant, both at Basic Chemistry Laboratory and Chemical Engineering Laboratory.

He interned at PT. Multi Nitrotama Kimia, producing mining explosives material (Ammonium Nitrate) in Cikampek, Indonesia in July 2013 for almost one month. In April 2014, he joined the seminar held by Indonesia Ministry of Industry as the speaker with the theme "Biotechnology and Environmental Friendly Material" in Semarang, Indonesia. While he was attending college, he deepen the field of waste water treatment as his final project with the title "Synthesis of Hydroxyapatite from Egg-Shell Wastes as Adsorbent of Solvent Dyes".

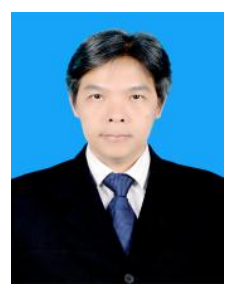

Henky Muljana obtained the B.Sc degree in chemical engineering from Parahyangan Catholic University, Bandung in 1998. He continue his study at University of Groningen, the Netherlands, to obtain his master degree in chemical engineering in 2003 and his doctoral degree in 2010. Curently, he is an assistant professor in the Department of Chemical Engineering, Parahyangan Catholic University, Bandung, Indonesia. His research expertise is in the product engineering especially in the polymer and biopolymer modification. 